\title{
Changes in Aspergillus nidulans gene expression induced by bafilomycin, a Streptomyces-produced antibiotic
}

\author{
Petter Melin, Johan Schnürer and E. Gerhart H. Wagner \\ Author for correspondence: Petter Melin. Tel: +46 18 673212. Fax: +4618 673392. \\ e-mail: Petter.Melin@mikrob.slu.se
}

Department of

Microbiology, Swedish

University of Agricultural

Sciences, Box 7025,

5-750 07 Uppsala, Sweden

\begin{abstract}
In natural environments bacteria and filamentous fungi often compete for the same resources. Consequently, production of antibiotic secondary metabolites and defence mechanisms against these compounds have evolved in these organisms. An experimental model has been developed to study the response in fungi exposed to one such antibiotic. The filamentous fungus Aspergillus nidulans was treated with bafilomycin $B_{1}$, a Streptomyces-produced antibiotic which reduces radial growth rate and induces morphological changes in fungi. mRNA differential display was used to study changes in fungal gene expression. For five genes, changes in abundance of the corresponding mRNAs, directly or indirectly caused by bafilomycin, were observed. Of these, three were up-regulated and two repressed. With four of these the change in mRNA abundance measured ranged from 10- to 60-fold. However, for one gene the mRNA was only detected after bafilomycin treatment. One of the downregulated mRNAs encodes ASPND1, a glycoprotein that belongs to a known family of antigens identified in aspergilloma patients. One up-regulated mRNA shows sequence similarities, at the amino acid level, with a cell-wall protein of Saccharomyces cerevisiae. The remaining three genes were also cloned and sequenced; their sequences do not correspond to known genes in A. nidulans, and no similarities with published nucleotide or protein sequences in other organisms were found. These results indicate the feasibility of using mRNA differential display to study interactions between bacteria and filamentous fungi.
\end{abstract}

Keywords: Aspergillus nidulans, bacteria-fungi interactions, bafilomycin, mRNA differential display, quantitative RT-PCR

\section{INTRODUCTION}

In all natural ecosystems micro-organisms compete for nutrients and space. Secretion of antibiotic secondary metabolites can be one mechanism in the fight against other organisms. These metabolites are believed to have evolved through intra- and interspecies competition (Maplestone et al., 1992); their production may be constitutive or triggered upon competition. Many bacterial and fungal species have probably developed defence mechanisms against these substances.

In the search for fungal-antagonistic bacteria we pre-

The EMBL accession numbers for the new sequences in this paper are AJ011294, AJ011295, AJ011296 and AJ011297. viously isolated a strain, Streptomyces halstedii (K122), from mouldy grain that produces low molecular mass antifungal compounds. These induce remarkable morphological changes in the fungus with increased hyphal branching and reduced fungal radial growth. Similar effects were observed in several genera of filamentous fungi, e.g. Aspergillus, Fusarium, Heterobasidion, Mucor, Penicillium and Talaromyces (Frändberg \& Schnürer, 1998). The substances responsible for the effect were identified, using NMR and MS, as bafilomycin $B_{1}$ and bafilomycin $C_{1}$ (E. Frändberg and others, unpublished). Growth inhibitory effect and morphological change occur both when fungi are co-cultured with the Streptomyces isolate and when they are cultivated in bafilomycin-containing media.

The bafilomycins are macrolide antibiotics with a 16- 
membered lactone ring, initially isolated from Streptomyces griseus. Their growth-inhibitory effect has been demonstrated in several species of fungi, as well as in Gram-positive bacteria, but no change in branching pattern was reported in the filamentous fungi; bafilomycin $B_{1}$ and $C_{1}$ displayed higher inhibitory potency than bafilomycin $A_{1}$ (Werner et al., 1984). The bafilomycins have been shown to inhibit the activity of vacuolar ATPases (Bowman et al., 1988). It has been shown that vacuolar ATPases in a human cell line are more strongly inhibited by bafilomycin $A_{1}$ compared to the other bafilomycins (Papini et al., 1993). Bafilomycins $B_{1}$ and $C_{1}$ may affect fungi in a manner that differs from the effect of bafilomycin $A_{1}$ on these organisms. One interpretation of the finding that isolated vacuolar ATPases from Neurospora crassa could be inhibited by bafilomycin $\mathrm{A}_{1}$ in vitro whilst fungal cells were resistant to bafilomycin $\mathrm{A}_{1}$ treatment (Bowman et al., 1992) is that there are other target sites for this antibiotic in fungi. Nevertheless, the recent observation that another inhibitor of vacuolar ATPases, concanamycin A, causes similar morphological changes in N. crassa, and that resistant strains are mutated in the plasma membrane $\mathrm{H}^{+}$-ATPase, may indicate that the mutations compensate the organism for the inhibition of vacuolar ATPases (Bowman et al., 1997).

This work was initiated to address the question of the fungal targets of bafilomycin as well as the mechanism of action. As a first step, antibiotic-induced changes in fungal gene expression have been analysed. The rationale behind such an approach is that identification of genes whose expression is increased or decreased may provide clues about possible targets. Effects on gene expression may be direct (effects on gene regulation) or indirect, e.g. caused secondarily by a stress response that triggers a cascade of gene expression changes. In line with earlier findings, inhibition of vacuolar ATPases might act as such a trigger signal, but alternative effects are possible.

We have chosen the ascomycete Aspergillus nidulans (Eidam) Wint., teleomorph Emericella nidulans (Eidam) Vuill., as test organism for this study because it is wellcharacterized, having been used as a model organism for decades. Differences in gene expression induced by bafilomycin were assessed using the mRNA differential display method (Liang \& Pardee, 1992). This technique is well-suited to monitor both increases and decreases in the expression of, in principle, any gene.

\section{METHODS}

Organisms and culture conditions. A. nidulans (Glasgow wild-type; Fungal Genetic Stock Center A4, Kansas City, KS, USA) was inoculated at $5 \times 10^{4}$ spores $\mathrm{ml}^{-1}$ in a total volume of $8 \mathrm{ml}$ in $1.5 \%$ malt extract medium (Oxoid) in a $50 \mathrm{ml}$ Erlenmeyer flask. The culture was incubated at $25^{\circ} \mathrm{C}$ on a shaker (100 r.p.m.). After 24 h, bafilomycin $B_{1}$ (Fluka) was added to a concentration of $50 \mu \mathrm{g} \mathrm{ml}^{-1}$, and the culture was incubated for another $24 \mathrm{~h}$. This concentration of bafilomycin was chosen as a compromise between morphological effect and a reasonable growth. A control culture was grown under identical conditions except for the omission of bafilomycin. For cloning and plasmid propagation, Escherichia coli strain INV $\alpha \mathrm{F}^{\prime}$ was used.

RNA extraction. A. nidulans (bafilomycin-treated or control) was harvested on filter paper (Whatman no. 3). The fungus grew as pellets, and no sporulation was observed in either of the two treatments. RNA was extracted using an FP 120 FastPrep Cell Disruptor (Bio 101) according to the manufacturer's protocol. Approximately equal amounts of tissue were used for RNA extraction in both cases. Purified RNA was treated with RQ-DNase (Promega). Estimation of RNA concentration was performed on a $2 \%$ agarose gel after ethidium bromide staining.

RNA differential display. Differential display was performed essentially according to the RNAmap mRNA Differential Display system (GenHunter): cDNA was synthesized by reverse transcription of mRNA using, separately, four different anchor primers, $\mathrm{T}_{12} \mathrm{VG}, \mathrm{T}_{12} \mathrm{VA}, \mathrm{T}_{12} \mathrm{VT}$ and $\mathrm{T}_{12} \mathrm{VC}$ (Liang et al., 1993; Table 1), 0.5-1 $\mu$ g total RNA template in $20 \mu \mathrm{l}$ reactions $\left[50 \mathrm{mM}\right.$ Tris $/ \mathrm{HCl}, \mathrm{pH} 8 \cdot 3,3 \mathrm{mM} \mathrm{MgCl}_{2}$, $75 \mathrm{mM} \mathrm{KCl}, 10 \mathrm{mM}$ DTT, $1 \mu \mathrm{M}$ primer, $25 \mu \mathrm{M}$ dNTP, 200 units M-MLV reverse transcriptase (Promega)]. PCR was performed in a DNA Thermal Cycler 480 (Perkin-Elmer). The $\mathrm{T}_{12} \mathrm{VN}$ primers combined with one of five different arbitrary primers (AP-1 to AP-5; Table 1) were used in $20 \mu \mathrm{l}$ reactions [10 mM Tris $/ \mathrm{HCl}, \mathrm{pH} 8 \cdot 3,50 \mathrm{mM} \mathrm{KCl}, 1.5 \mathrm{mM} \mathrm{MgCl}_{2}$, $0.125 \mathrm{mg} \mathrm{BSA} \mathrm{ml}^{-1}, 2 \mu \mathrm{M}$ dNTP, $\left[{ }^{35} \mathrm{~S}\right] \mathrm{dATP} \alpha \mathrm{S}\left(\sim 5 \times 10^{4} \mathrm{~Bq}\right)$, $0 \cdot 2 \mu \mathrm{M}$ AP, $1 \mu \mathrm{M} \quad \mathrm{T}_{12} \mathrm{VN}$ and 1 unit Taq polymerase (Amersham)]; 40 cycles $\left(94^{\circ} \mathrm{C} 30 \mathrm{~s}, 40^{\circ} \mathrm{C} 120 \mathrm{~s}\right.$ and $72{ }^{\circ} \mathrm{C}$ $60 \mathrm{~s})$. Reactions were run in duplicate to reduce the likelihood of PCR artefacts. PCR products were separated on $6 \%$ denaturing polyacrylamide gels. Gels were dried and exposed to X-ray film overnight.

Cloning of differentially displayed gene fragments. PCR products corresponding to differentially expressed genes were excised from the gel, extracted by boiling in $100 \mu \mathrm{TE}(10 \mathrm{mM}$ Tris/ $\mathrm{HCl}, \mathrm{pH} 8 \cdot 1,1 \mathrm{mM}$ EDTA) and ethanol precipitated with $10 \mu \mathrm{l} 3 \mathrm{M}$ sodium acetate, $5 \mu$ l glycogen $\left(10 \mathrm{mg} \mathrm{m}^{-1}\right)$ and $450 \mu \mathrm{l}$ ethanol. DNA was resuspended in $10 \mu \mathrm{l} \mathrm{H}_{2} \mathrm{O}$, and $5 \mu \mathrm{l}$ was used for PCR reamplification in a Rapid cycler (Idaho Technologies) using the same set of primers in $50 \mu \mathrm{l}$ reactions (10 mM Tris/ $\mathrm{HCl}, \mathrm{pH} 8.3,50 \mathrm{mM} \mathrm{KCl,} 2.5 \mathrm{mM} \mathrm{MgCl} \mathrm{Mg}_{2}$, $0.125 \mathrm{mg} \mathrm{BSA} \mathrm{ml}^{-1}, 0 \cdot 2 \mathrm{mM}$ dNTP, $0 \cdot 2 \mu \mathrm{M} \mathrm{AP}, 1 \mu \mathrm{M} \mathrm{T} \mathrm{T}_{12} \mathrm{VN}$, 2.5 units Taq polymerase); 40 cycles of $94^{\circ} \mathrm{C}$ for $15 \mathrm{~s}, 38^{\circ} \mathrm{C}$ for $60 \mathrm{~s}$ and $72{ }^{\circ} \mathrm{C}$ for $22 \mathrm{~s}$, followed by $60 \mathrm{~s}$ at $72^{\circ} \mathrm{C}$. The products were purified from a $2 \%$ agarose gel and cloned into a pGEM-T vector (Promega).

DNA sequence analysis. The DNA sequences of the inserts were determined on an ABI 377 DNA Sequencer (PerkinElmer) using dye terminator nucleotides and M13 Forward and Reverse sequencing primers, respectively (Table 1). Sequences were analysed for correct sequence of the PCR primers and compared to published sequences $(\mathrm{EMBL}$, GenBank, DDBJ).

Independent confirmation of differential display. A set of labelled RT-PCR reactions was performed with newly designed primers unique for each individual fragment (primer binding sites located within the obtained fragments; Table 1). RNA templates were made from new independent fungal cultures, in order to ensure that increases/decreases in the intensity of candidate bands were reproducibly obtained when using identical protocols. After reverse transcription, the resulting cDNAs were serially diluted from 10 to 10000 times. 
Table 1. Oligodeoxyribonucleotides used in this study

\begin{tabular}{|c|c|}
\hline Primer name & Sequence $\left(5^{\prime}-3^{\prime}\right)$ \\
\hline $\mathrm{T}_{12} \mathrm{VG}$ & TTT TTT TTT TTT VG* \\
\hline $\mathrm{T}_{12} \mathrm{VA}$ & TTT TTT TTT TTT VA* \\
\hline $\mathrm{T}_{12} \mathrm{VT}$ & TTT TTT TTT TTT VT* \\
\hline $\mathrm{T}_{12} \mathrm{VC}$ & TTT TTT TTT TTT VC* \\
\hline AP-1 & AGC CAG CGA A \\
\hline AP-2 & GAC CGC TTG T \\
\hline AP-3 & AGG TGA CCG T \\
\hline AP-4 & GGT ACT CCA C \\
\hline AP-5 & GTT GCG ATC C \\
\hline $\mathrm{M} 13 \mathrm{~F}$ & GTT TTC CCA GTC ACG AC \\
\hline M13R & CAG GAA ACA GCT ATG AC \\
\hline NS7 & GAG GCA ATA ACA GGT CTG TGA TGC \\
\hline NS8 & TCC GCA GGT TCA CCT ACG GA \\
\hline AAP & GGC CAC GCG TCG ACT AGT ACG GGI† IGG† GI I \\
\hline AUAP & GGC CAC GCG TCG ACT AGT AC \\
\hline breAF & TTG GGT GTG TTG GTG GAG \\
\hline breAR & GCA CGA ATC GTC TGA AGG \\
\hline breAnested & CTC CTC AGC CGC CTC ATC CT \\
\hline breBF & CGC TTG TTG CAT TAG AAG ACC \\
\hline breBR & TGC GGT TGA TGT TTG GCT \\
\hline breBnested & GCA TCT ATT CCG ACA TCT TCA \\
\hline breBnested2 & CGC CAA AGG AGA TTA TGA CA \\
\hline breBnested3 & CCT GGG CTG CCA CTA ATC TG \\
\hline binAF & TCG TTA GTT CTG CTC GTC TGC \\
\hline binAR & CTC AAA TAG AAC AAC GCA CCA ACG \\
\hline binAnested & TAT CAT CTG TTT TCG CCT GGG TC \\
\hline binAnested2 & CGC ACT AGC AGA CGA GCA GA \\
\hline binAnested3 & CCT CTC TGC ACT GCA ATA TCC \\
\hline binAnested 4 & CAA GTG CAT CTC AAT CTC TCC \\
\hline $\operatorname{binBF}$ & AGA CCG AGA ACC CTA TTG \\
\hline binBR & CCC AAT AAA TTA GGA CTT TA \\
\hline binBnested & CGG TCT AAT TGA TAA TAT ACA \\
\hline binBnested2 & GGT TGG CGA CAC CAG CAG AG \\
\hline binBnested3 & ATC AAT GCT GTT GGG ACA AG \\
\hline binCF & TGA ATG TGA TGG AGC TGG A \\
\hline binCR & ACC GTA CTG AAC CGT ACT GC \\
\hline binCnested & GTG CAG CAA ATT CGG ATG GAT C \\
\hline binCnested2 & CTC CAT CAC ATT CAA CCA GG \\
\hline binCnested3 & GAA AGA AGA CCT CAA CGC AG \\
\hline binCnested4 & CAA GGG AGG TCT TTT CAA GG \\
\hline
\end{tabular}

*V denotes $\mathrm{A}, \mathrm{C}$ or $\mathrm{G}$.

†I denotes inosine.

PCR was performed in a Rapid cycler using the new, insertspecific, primer combinations in $10 \mu \mathrm{l}$ reactions $[2 \mu \mathrm{l}$ diluted template, $10 \mathrm{mM}$ Tris/ $\mathrm{HCl}, \mathrm{pH} 8.3,50 \mathrm{mM} \mathrm{KCl}, 1.5-2.5 \mathrm{mM}$

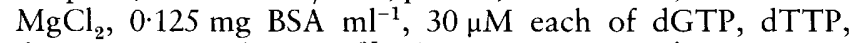
$\mathrm{dCTP}, 15 \mu \mathrm{M}$ dATP $+\left[{ }^{35} \mathrm{~S}\right] \mathrm{dATP} \alpha \mathrm{S}\left(\sim 5 \times 10^{4} \mathrm{~Bq}\right), 1 \mu \mathrm{M}$ primers and 0.5 units Taq polymerase $] ; 30-40$ cycles $\left(94^{\circ} \mathrm{C}\right.$ for $1-5 \mathrm{~s}, 42-55^{\circ} \mathrm{C}$ for $0 \mathrm{~s}$ and $72^{\circ} \mathrm{C}$ for $4-8 \mathrm{~s}$ ). Denaturing time, annealing temperature and magnesium concentration were template- and primer-dependent, while elongation time was varied depending on template length. Band intensities were quantified on a PhosphorImager (Molecular Dynamics). The relative change in abundance of mRNA was calculated as the mean ratio between band intensities (treated divided by control). By simultaneously synthesizing cDNA from a segment of $18 \mathrm{~S}$ rRNA, RT-PCR (primers NS7 and NS8; White et al., 1990; Table 1) was used to generate an internal standard to correct for variations in the amount of total RNA used in the different assays.

Cloning of full-length cDNA. A $5^{\prime}$ Rapid Amplification of cDNA Ends ( $5^{\prime}$ RACE) system (Gibco-BRL) was used to amplify full-length cDNAs. Briefly, reverse transcription of total RNA, using a fragment-specific primer, was followed by C-tailing of the $3^{\prime}$ end of first-strand CDNA. PCR amplification 
was performed with a set of nested primers (Table 1), whose binding sites were located 3 ' of the first primer site on the cDNA, and a set of primers which anchor the C-tail, AAP and AUAP (Table 1). The PCR products were cloned into a pGEM-T Easy Vector (Promega), and sequences were determined using M13 primers and sequence-specific internal primers.

\section{RESULTS}

\section{Bafilomycin $B_{1}$ induces morphological changes and represses growth in $A$. nidulans}

In order to mimic the interaction between $S$. halstedii and fungi, we grew $A$. nidulans in a medium containing bafilomycin $\mathrm{B}_{1}$, a specific Streptomyces antibiotic. When the fungus was grown in the presence of bafilomycin, it showed a dramatic morphological change (Fig. 1). This bafilomycin-dependent effect is similar to the response observed in other fungi grown in the presence of $S$. halstedii (Frändberg \& Schnürer, 1998). In the presence of bafilomycin, fungal growth was severely inhibited, so that a sufficient amount of RNA could not be extracted. We overcame this problem by adding the antibiotic to the medium $24 \mathrm{~h}$ after inoculation of fungal spores. Total RNA from treated and untreated fungi was then extracted and used in subsequent experiments as summarized schematically in Fig. 2.

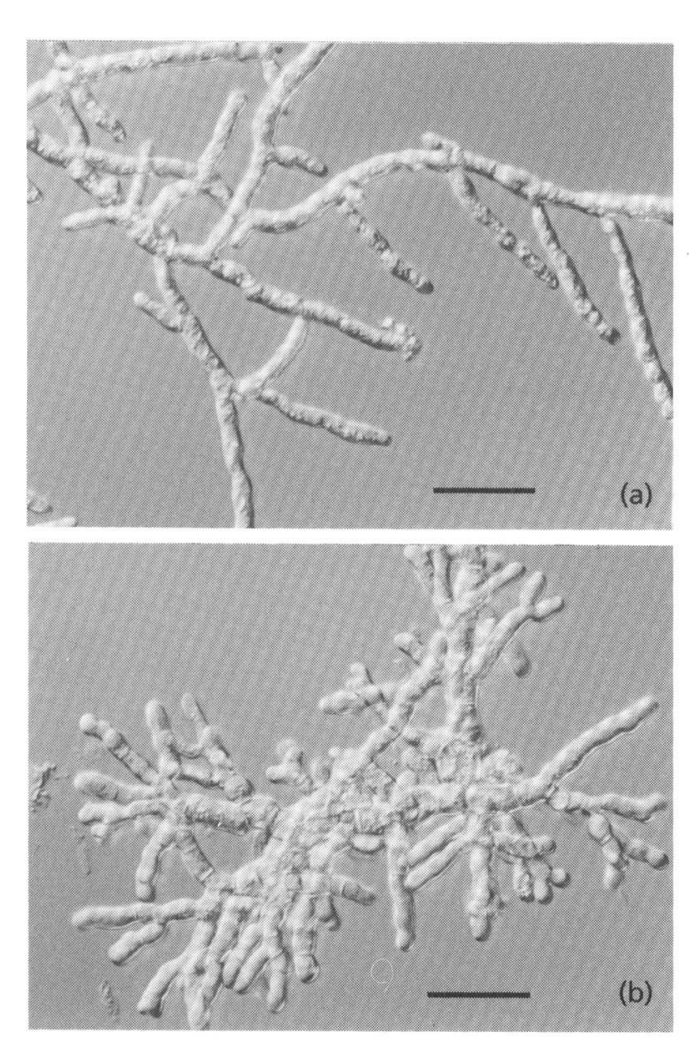

Fig. 1. Effect of bafilomycin $B_{1}$ on $A$. nidulans hyphal morphology. (a) Control hyphae. (b) A. nidulans treated with $25 \mu \mathrm{g}$ bafilomycin $\mathrm{B}_{1} \mathrm{ml}^{-1}$. Bar, $20 \mu \mathrm{m}$.

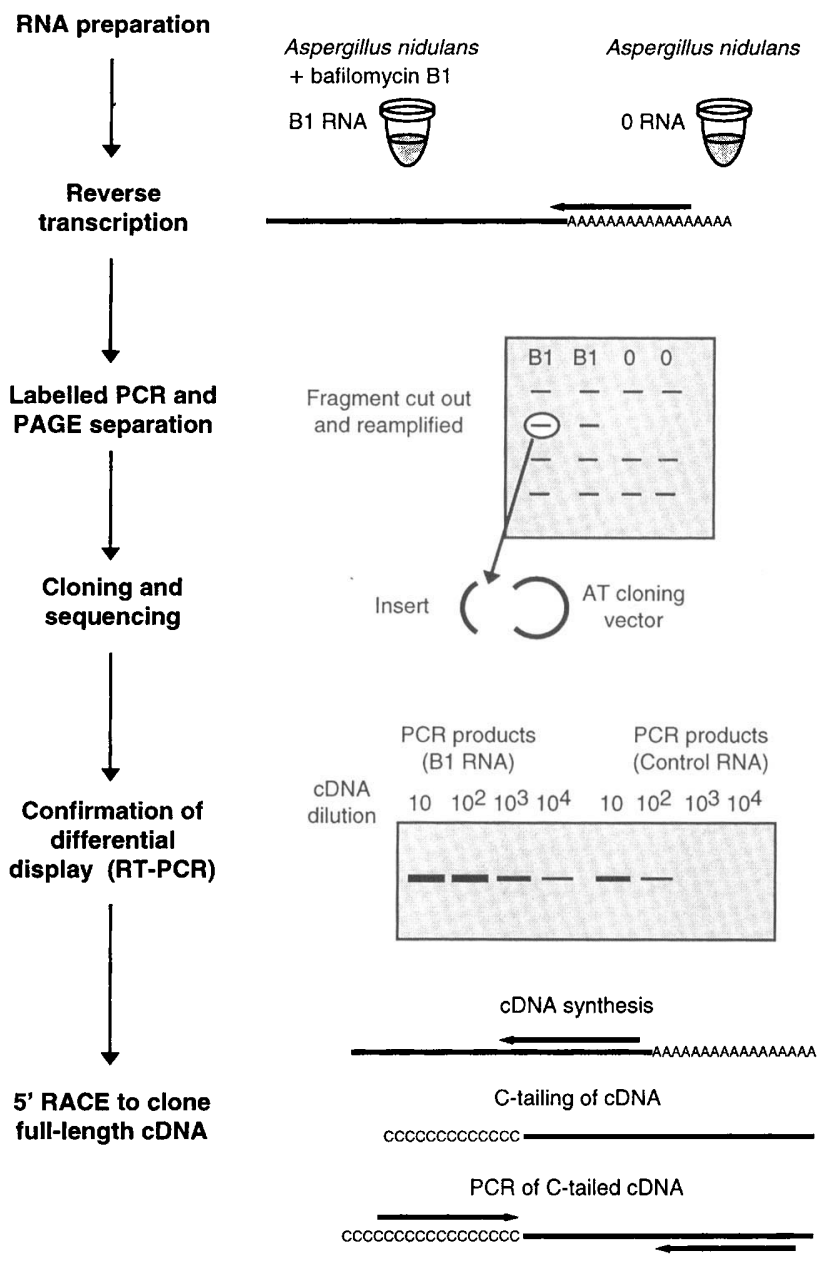

Fig. 2. Schematic overview of the experimental procedure.

\section{Gene expression changes dependent on bafilomycin treatment of $A$. nidulans assessed by mRNA differential display}

We used mRNA differential display to identify genes whose expression is changed after treatment with bafilomycin (see Methods). The selection of candidate bands was based on a comparison of duplicate band patterns generated from the two different RNA samples, obtained from bafilomycin-treated and untreated fungal cultures. Labelled fragments that showed either increased or decreased intensity were chosen. Fig. 3 shows characteristic segments of such autoradiograms. The 20 different primer combinations used in this procedure resulted in 30 fragments judged as being differentially displayed (data not shown). Of these, 21 were successfully cloned and sequenced. These inserts were from 150 to $500 \mathrm{bp}$ in length. Both the $\mathrm{T}_{12} \mathrm{VN}$ and the AP sequences were found in 17 of these fragments, confirming the experimental strategy. These inserts were selected for further studies. The remaining four fragments did not contain the $\mathrm{T}_{12} \mathrm{VN}$ primer sequence and were therefore excluded from further analysis. 

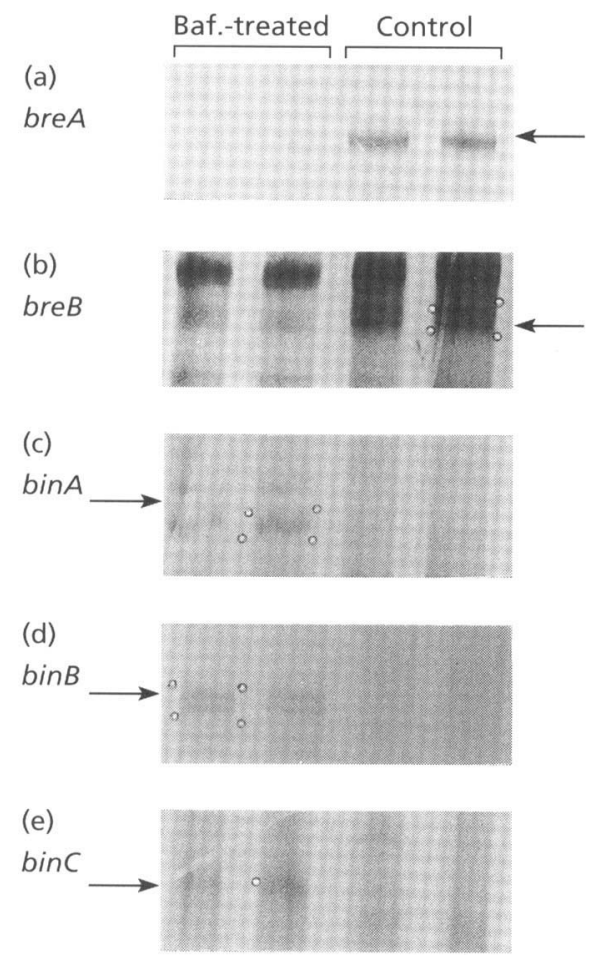

Fig. 3. Differential display pattern of the indicated fragments. (a-e) Autoradiogram segments of duplicate reactions of bafilomycin-treated (left) and control (right) RNA templates. The denotation of the fragments corresponds to that of the inserts whose sequences were determined (see Results). Primer combinations used to obtain the bands shown were: $\mathrm{T}_{12} \mathrm{VC}+\mathrm{AP}-5 \quad$ (a); $\quad \mathrm{T}_{12} \mathrm{VG}+\mathrm{AP}-2 \quad$ (b, c); $\mathrm{T}_{12} \mathrm{VG}+\mathrm{AP}-3 \quad$ (d); $T_{12} V T+A P-3$ (e). Fragments chosen for subsequent experiments are indicated by arrows.

\section{Quantitative RT-PCR analysis of specific candidate mRNAs confirms differences in gene expression}

Successful cloning of fragments that were identified based on increased or decreased band intensities as in Fig. 3 does not unambiguously demonstrate altered gene expression. Since differential display is known to result in varying numbers of false positives, quantitative RTPCR was used to retest the candidate gene sequences. Here, primers based on sequences internal to the various inserts (i.e. different from and independent of the first set of primers) were used in RT-PCR. This was done by appropriate parallel ( \pm bafilomycin) cDNA dilutions and by measuring the relative band intensities of the resulting labelled PCR products (see Methods). For five out of 17 fragments, the results obtained indicate differential expression (Fig. 4). In three cases upregulation by bafilomycin is observed (bafilomycininduced genes; bin); the two other cases indicate downregulation (bafilomycin-repressed genes; bre). The upregulated transcript of one gene $($ bin $C)$ was detected even after $10^{4}$ times dilution of cDNA, whereas no corresponding bands were visible in the control samples (Fig. 4e), suggesting more than a 1000 -fold increased abundance of the mRNA after bafilomycin treatment.
For the other four sequences the increase/decrease of mRNA was estimated to be between 10- and 60-fold (Fig. 4a-d). An internal standard, generated from $18 \mathrm{~S}$ rRNA sequences, resulted in bands of almost equal intensity for the two treatments (Fig. 4f), indicating that approximately the same amount of purified RNA had been used for reverse transcription prior to quantitative PCR.

\section{Determination of gene sequences in A. nidulans whose expression is affected by bafilomycin}

The design of the above protocol is only expected to yield short sequences corresponding to the $3^{\prime}$ end of the respective mRNA. In organisms for which complete genomic sequences are not available, it is therefore useful to obtain full-length cDNA clones in order to be able to identify putative protein products encoded based on sequence comparison with other organisms. Therefore, we performed a $5^{\prime}$ RACE procedure for the mRNAs. The same primers that were used for reverse transcription before quantitative PCR were used in this protocol, as well as a set of nested primers (Table 1) which was found to be required for PCR reamplification of the cDNAs. We were able to obtain cDNA clones for all five mRNAs. Based on the fact that the same $5^{\prime}$ mRNA ends were obtained after repeated independent cloning with new sets of nested primers and that, with one exception (breB), the genes contain typical ORFs, the characteristics of the cDNAs suggest them to be fulllength (Table 2).

Only one sequence (bre $A$ ) scored a perfect match in available databases. It corresponds to aspnd1, a gene encoding a glycoprotein (ASPND1; Calera et al., 1997). The aspnd1-like mRNA sequence identified here differs from the one published previously in that it is shortened by approximately $120 \mathrm{bp}$ at its $3^{\prime}$ end. Since the missing segment is located outside the coding region, this may be due to a strain difference. We have cloned and sequenced full-length cDNA to confirm aspnd1 identity (data not shown).

The second down-regulated mRNA $($ breB $)$ was identified as a cDNA which was 1273 nucleotides in length. This sequence shows no similarity to published genes. The longest ORF, located approximately in the middle of the cloned cDNA, was found to comprise 138 codons. This ORF does not contain the most 5'-proximal methionine of the transcript.

One gene, corresponding to an up-regulated mRNA (bin $B)$, encodes a transcript of 738 nucleotides. Its deduced amino acid sequence (BinB) is, near its $\mathrm{N}$ terminus, similar (Fig. 5) to that of a cell-wall mannoprotein of Saccharomyces cerevisiae (Cwp1p; van der Vaart et al., 1995). The remaining two bafilomycininduced genes encode transcripts of 488 (binA) and 412 (binC) nucleotides. These two short mRNAs show no resemblance to published sequences. The change in their mRNA abundance (Fig. 4c, e) is more significant than that of bre A, breB and $\operatorname{bin} B$ (Fig. $4 \mathrm{a}, \mathrm{b}, \mathrm{d}$ ). 


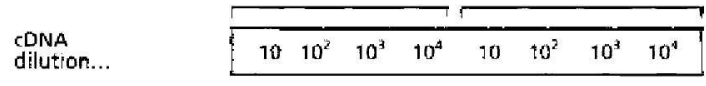

(a) breA

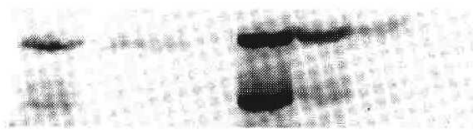

Ratio of

treated/untreated.

$1: 20$

(d) $\operatorname{bin} B$

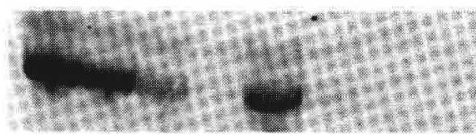

Ratio of

treated/untreated.

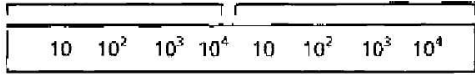

(b) breB

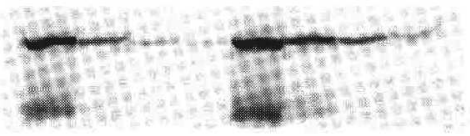

$1: 10$

(e) binc

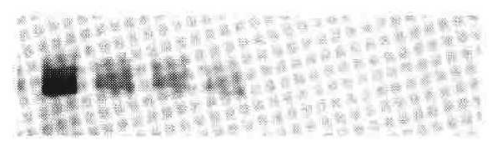

$>1000: 1$

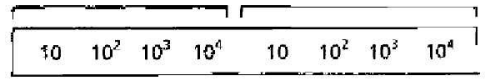

(c) $\operatorname{bin} A$

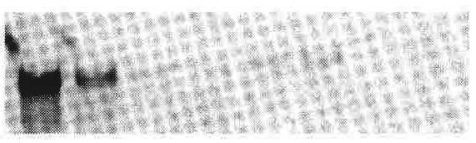

$60: 1$

(f) $18 \mathrm{~S}$ rRNA

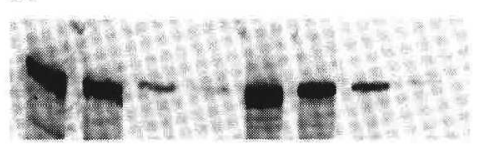

$1: 1$

Fig. 4. Quantification of relative mRNA levels by RT-PCR. Quantitative RT-PCR was performed as described in Methods. (a-e) Autoradiograms of RT-PCR experiments performed with primer sets specific for the genes indicated. (f) Contral amplification of an 185 rRNA segment. Band intensities were quantified by Phosphorlmager analysis; expression ratios (treated/untreated) were calculated and are shown below the autoradiograms.

Table 2. Summary of mRNA sequences whose abundance is affected by bafilomycin

\begin{tabular}{|c|c|c|c|c|c|}
\hline Gene & Response & Length (nt) & $\begin{array}{l}\text { Longest } \\
\text { ORF (nt) }\end{array}$ & $\begin{array}{l}\text { No. of } \\
\text { codons }\end{array}$ & $\begin{array}{c}\text { Accession } \\
\text { no. }\end{array}$ \\
\hline breA/aspnd1 & Down-regulated & 894 & $10-844$ & 278 & $Z 80229$ \\
\hline breB & Down-regulated & 1273 & $627-1041$ & 138 & A J011294 \\
\hline $\operatorname{bin} A$ & Up-regulated & 488 & $44-308$ & 88 & A J01 1295 \\
\hline $\operatorname{bin} B$ & Up-regulated & 737 & $208-657$ & 18.3 & AJ011296 \\
\hline $\operatorname{binc}$ & Up-regulated & 412 & $67-241$ & 58 & AJ011297 \\
\hline
\end{tabular}

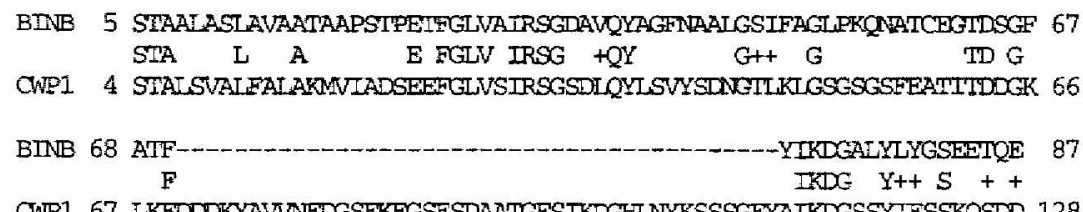

CWP1 67 IKFDDDKYANNFDGSFKEGSESLAATGFSIKDGHLNYKSSSGFYATKDGSSYIFSSKQSDD 128
Fig. 5. Comparison of the primary sequence of BinB and Cwp1p, a cell-wall protein of Saccharomyces cerevisiae. Identical and semi-conserved amino acids are indicated. The dashed line indicates a gap in the BinB sequence.

\section{DISCUSSION}

In this communication we have shown that bafilomycin $\mathrm{B}_{1}$ causes changes in gene expression in $A$. nidulans. This is to our knowledge the first report on the use of differential display for characterization of fungal genes whose expression is changed after encountering bacterial metabolites, although differential display has been used to study other interactions between microbes and other organisms, c.g. fungi-plants (Benito et al., 1996; Wang \& Perlin, 1998) and bacteria-plants (Goormachtig et al., 1995).

We have identified five sequences corresponding to genes whose expression was changed by bafilomycin. The surprisingly small number of verifiable changes might imply that there are only a limited number of genes affected by the antibiotic. However, it is likely that not all of the putative affected genes were scored due to limitations inherent in the experimental strategy. It has previously been reported that differential display preferentially detects abundant mRNAs, mainly because of the low nucleotide concentrations used in the protocol (Bertioli et al., 1995). Hence, it is likely that other affected genes have escaped detection by this merhod. The number of affected genes identified might have been higher if a greater number of different arbitrary primers had been used. Similarly, our analysis would most likely have failed to identify changes in faint bands it the corresponding fragments co-migrated with more abundant fragments. A further limitation of this approach 
concerns possible post-transcriptional regulation. For example, translational up- or down-regulation of an mRNA, as in the case of the transferrin mRNA (Hentze \& Kühn, 1996), would probably remain undetected. Likewise, direct effects of bafilomycin on the activity of proteins would fail to result in RT-PCR signals.

Another limitation of differential display is the generation of significant numbers of false positives. Candidate bands have to be confirmed by Northern blot or quantitative RT-PCR analysis. In the present report differential expression could be confirmed for only five out of 17 fragments, a proportion reported to be within the normal range (Liang et al., 1993).

Although we have shown that bafilomycin both induces and represses gene expression in A. nidulans, it is premature to draw conclusions about the mechanisms underlying differential expression. It is possible that the expression change reflects indirect effects of reduced growth rate, e.g. caused by inhibition of vacuolar ATPases. Such a growth-inhibitory effect has previously been demonstrated in $N$. crassa for bafilomycin $\mathrm{A}_{1}$ (Bowman et al., 1992) and concanamycin A (Bowman et al., 1997). Bafilomycin may also directly affect the synthesis or stability of specific mRNAs, possibly mediated through effects on the activity of regulatory proteins.

Among the five genes whose expression was found to be affected by bafilomycin one had previously been identified. The function of this gene, aspnd1, whose expression is down-regulated by bafilomycin, is still elusive. Its gene product, ASPND1, is recognized by antibodies from aspergilloma patients (Calera et al., 1997). The fact that ASPND1 is a glycoprotein and an antigen suggests that the protein is associated with the cell wall. Transcription of aspnd1 is strongly suppressed by micromolar amounts of zinc, which suggests the gene product to be a zinc-binding protein, involved in zinc uptake from the surrounding medium (R. López-Aragón $\&$ F. Leal, personal communication).

One of the up-regulated genes $(\operatorname{bin} B)$ shows similarities at the amino-acid level to Cwp1p, a yeast mannoprotein which is located in the cell wall. Altered composition of cell-wall proteins may be a reflection of the observed change in hyphal morphology after bafilomycin treatment (Fig. 1; E. Frändberg and others, unpublished). It has also been reported that stress causes changes in the composition of cell-wall mannoproteins in yeast (Parascandola et al., 1997). If the significant amino acid sequence similarity between BinB and Cwp1p is indicative of a similar function, up-regulation may be a manifestation of bafilomycin-induced stress in $A$. nidulans.

The other three gene sequences obtained display no similarities to known sequences in databases. This suggests that either they represent previously unknown genes, or the present work has failed to obtain errorfree, full-length cDNAs. It is conceivable that secondary structures in mRNA could have impeded reverse transcription, resulting in $5^{\prime}$-shortened cDNAs.
Interestingly, one of these unknown genes $(\operatorname{bin} C)$ shows a dramatic bafilomycin-dependent up-regulation, while in the absence of bafilomycin treatment its transcript was undetectable by RT-PCR. This on/off situation indicates that bafilomycin treatment can cause more than a gradual change in gene expression.

This study indicates that it is feasible to monitor changes in gene expression occurring in bacteria-fungi interactions. To test the strategy under defined conditions, we deliberately initiated this work using the compound responsible for the biological (antagonistic) effect rather than co-cultivation with the bacterial strain. Although we were able to identify five genes that displayed altered expression, one cannot be certain that the gene products encoded represent bona fide targets or are regulatory proteins involved in the phenotypic change. To obtain additional information about putative targets of the antibiotics, we will (i) attempt shotgun cloning of $A$. nidulans genes and test for increased resistance (i.e. partial rescue by overexpression of key genes), and (ii) introduce fusions consisting of the promoter regions of the genes identified here and a reporter gene, scoring for bafilomycin-dependent change in expression. Since we are convinced that the present work only detected a subset of affected genes, we have recently initiated a proteome analysis to monitor expression changes at the protein level. We expect that the combination of these approaches will help to clarify whether the genes identified in the present work represent targets of the antibiotic or whether their altered expression is a secondary consequence of the phenotypic changes induced.

\section{ACKNOWLEDGEMENTS}

This research was financed by the Swedish Council for Forestry and Agricultural Research.

\section{REFERENCES}

Benito, E. P., Prins, T. \& van Kan, J. A. (1996). Application of differential display RT-PCR to the analysis of gene expression in a plant-fungus interaction. Plant Mol Biol 32, 947-957.

Bertioli, D. J., Schlichter, U. H. A., Adams, M. J., Burrows, P. R., Steinbiss, H. H. \& Antonny, J. F. (1995). An analysis of differential display shows a strong bias towards high copy number mRNAs. Nucleic Acids Res 23, 4520-4523.

Bowman, E. J., Siebers, A. \& Altendorf, K. (1988). Bafilomycins: a class of inhibitors of membrane ATPases from microorganisms, animal cells, and plant cells. Proc Natl Acad Sci USA 85, 7972-7976.

Bowman, B. J., Dschida, W. J. \& Bowman, E. J. (1992). Vacuolar ATPase of Neurospora crassa: electron microscopy, gene characterization and gene inactivation/mutation. J Exp Biol 172, 57-66.

Bowman, E. J., O'Neill, F. J. \& Bowman, B. J. (1997). Mutations of pma-1, the gene encoding the plasma membrane $\mathrm{H}^{+}$-ATPase of Neurospora crassa, suppress inhibition of growth by concanamycin A, a specific inhibitor of vacuolar ATPases. J Biol Chem 272, 14776-14786.

Calera, J. A., Ovejero, M. C., López-Medrano, R., Segurado, M., Puente, P. \& Leal, F. (1997). Characterization of the Aspergillus 
nidulans aspnd1 gene demonstrates that the ASPND1 antigen, which it encodes, and several Aspergillus fumigatus immunodominant antigens belong to the same family. Infect Immun 65, 1335-1344.

Frändberg, E. \& Schnürer, J. (1998). Antifungal activity of chitinolytic bacteria isolated from airtight stored cereal grain. Can J Microbiol 44, 121-127.

Goormachtig, S., Valerio Lepiniec, M., Szczyglowski, K., Van Montagu, M., Holsters, M. \& de Bruijn, F. J. (1995). Use of differential display to identify novel Sesbania rostrata genes enhanced by Azorbizobium caulinodans infection. Mol PlantMicrobe Interact 8, 816-824.

Hentze, M. V. \& Kühn, L. C. (1996). Molecular control of vertebrate iron metabolism: mRNA-based regulatory circuits operated by iron, nitric oxide, and oxidative stress. Proc Natl Acad Sci USA 93, 8175-8182.

Liang, P. \& Pardee, A. B. (1992). Differential display of eukaryotic messenger RNA by means of the polymerase chain reaction. Science 257, 967-971.

Liang, P., Averboukh, L. \& Pardee, A. B. (1993). Distribution and cloning of eukaryotic mRNAs by means of differential display: refinements and optimization. Nucleic Acids Res 21, 3269-3275.

Maplestone, R. A., Stone, M. J. \& Williams, D. H. (1992). The evolutionary role of secondary metabolites - a review. Gene 115 , 151-157.
Papini, E., de Benard, M., Bugnoli, M., Milia, E., Rappuoli, R. \& Montecucco, C. (1993). Cell vacuolization induced by Helicobacter pylori: inhibition by bafilomycins A1, B1, C1 and D. FEMS Microbiol Lett 113, 155-160.

Parascandola, P., de Alteriis, E., Sentandreu, R. \& Zueco, J. (1997). Immobilization and ethanol stress induce the same molecular response at the level of the cell wall in growing yeast. FEMS Microbiol Lett 150, 121-126.

van der Vaart, J. M., Caro, L. H. P., Chapman, J. W., Klis, F. M. \& Verrips, C. T. (1995). Identification of three mannoproteins in the cell wall of Saccharomyces cerevisiae. J Bacteriol 177, 3104-3110.

Wang, L. \& Perlin, M. H. (1998). Isolation of a novel gene (HSGc11) whose expression is apparently limited to the hyphal stage of Microbotryum violaceum. Int J Plant Sci 159, 206-212.

Werner, G., Hagenmaier, H., Drautz, H., Baumgartner, A. \& Zähner, H. (1984). Bafilomycins, a new group of macrolide antibiotics. J Antibiot 38, 110-117.

White, T. J., Bruns, T., Lee, S. \& Taylor, J. (1990). Amplification and direct sequencing of fungal ribosomal RNA genes for phylogenetics. In PCR Protocols: a Guide to Methods and Applications, pp. 315-322. Edited by M. A. Innis, D. H. Gelfand, J. J. Sninsky \& T. J. White. San Diego: Academic Press.

Received 9 November 1998; revised 31 December 1998; accepted 18 January 1999. 